\title{
Study of the Impact of Construction Quality Management on the Project
}

\author{
Cost \\ Peng Li ${ }^{1}$ \\ ${ }^{1}$ Huaxin Institute, Hebei College of Geology, Shijiazhuang, Hebei, 050700
}

\section{KEYWORDS: Construction Site; Quality Management; Project Cost}

\begin{abstract}
Cost control is an important part of the economic benefits in the real estate development business management and effective cost control is much important to improve the market competitiveness of real estate enterprises. Based on the real estate development process, this paper puts forward measures to strengthen control of the entire process viewpoint priorities various stages of project development cost dynamic control methods from the decision-making phase of the project, planning and design phase, bidding phase, construction phase and completion and acceptance of different cost control. By dynamically controlling all stages of real estate development enterprise cost management, reduce project costs thereby enhancing the core competitiveness of the real estate development enterprises.
\end{abstract}

\section{Introduction}

Project Cost Management refers to the cost of the project resource planning in order to ensure the project does not exceed the actual project budget preparation undertaken, the project cost estimates, project cost budget and project cost control and other aspects of management processes and activities. Breakeven cost of real estate projects directly related to the efficiency of enterprises, the fate and future, directly affect the economic efficiency of enterprises. Cost effective project management, real estate business profit guarantee. How to reduce the cost of the project, to strengthen project cost management, real estate enterprises to improve efficiency, theory and engineering practice have made many useful exploration. But previous cost management model, the lack of dynamic tracking management project costs and effective management tools, making the cost management functions cannot be well achieved, it is the thesis research.

\section{Relations between Construction Quality and Construction Costs}

In building construction, the state has adopted various policies ordered construction units focus on ensuring the quality of construction, which is bound to increase the cost estimates and construction unit construction cost control efforts. In the whole construction cost, the construction materials and equipment costs account for more than $60 \%$ of the total cost of construction, a large proportion. Therefore, the construction unit to ensure the quality of construction projects at the same time, should the construction materials and equipment as the focus of lower construction costs, the greater energy into the construction materials and equipment. According to China's construction market research analysis, many construction units to focus only on the price of construction materials and equipment, and did not pay attention to the rationality of the selected material properties and construction equipment, construction material and no operation and maintenance of equipment to effectively manage (including materials supply and demand, type, routine 
maintenance and storage of construction equipment, etc.). As a construction unit, in order to ensure the quality of construction, must be carried out on the construction site management capabilities and responsibilities of construction management personnel with the necessary training, in particular to strengthen the management of construction materials and construction equipment, not only to provide basic support for the continuous construction of construction projects, construction unit construction site management system but also to develop realistic and detailed collection of building materials and construction equipment supply manufacturers, a careful review of the qualification supply units, product quality and price, a comprehensive analysis into account, choose to meet the requirements of construction quality on the basis of, try to choose lower-priced supply manufacturers, to reduce construction costs radically.

In the construction process of the construction project selection, the state has promulgated a series of laws, regulations and construction specifications and construction standards Atlas supporting the publication of a number of further improve the order of the construction market. Construction Engineering Construction Technology according to the specific circumstances of construction projects considering the selected reference construction budget and offer scope and national construction costs related to organizational design specifications, prepare construction cost estimates. And the whole construction process of cost control, including not only material and equipment, more importantly, is the responsibility of managers to strengthen the ability to control costs and control, not only for the whole construction process quality control, but also with the actual situation of the construction carried out effective cost control, to ensure construction quality, as far as possible to reduce construction costs, enhance the market competitiveness of the construction unit.

Quality Control of Construction Engineering of the whole process must be in accordance with the relevant national norms and quality control requirements, the scientific development in line with the practical engineering quality control system, to strengthen the skills and sense of quality control construction management, and strengthen each step of construction supervisors on construction monitoring and thorough investigation of the strength and sense of responsibility, the quality of the project to prevent and control implemented. Strict implementation of national construction standards and measures to effectively reduce the construction process materials, labor, machinery and consumption, thus effectively reducing the cost of building construction. In building construction, construction management and supervision units required by law to take up the responsibility to review the construction unit qualification and the quality and performance of construction materials, to crack down on the use of inferior materials in construction, and even cutting corners, not only affect the construction quality and safety, but also damage to the reputation of the construction unit, not only failed to reduce construction costs and fundamentally, on the contrary, there may be due to quality issues, leading to the construction of a process to stop or rework, greater capital investment may increase construction costs.

In the actual building construction, must be scientifically and effectively handle the relationship between the quality of construction and construction costs. Any one of the factors in building construction changes will affect the normal construction of other factors, changes in the relationship between construction costs and construction quality as well. Therefore, we must carry out the construction quality and cost-effective coordination in ensuring construction quality while minimizing construction costs. Measures to strengthen the whole process of project quality control management. Gradually strengthen the construction quality control management efforts, the stringent requirements of construction management and construction supervision personnel, strengthen the construction quality control and responsibility refinement construction quality and 
accountability, strict implementation of quality vote veto; strengthen the overall quality of construction management personnel, construction site managers and improve skills, strengthen the construction unit leaders and members at all levels of cost management, training, quality control, construction management and business skills, establish quality awareness and improve construction quality, management and operational skills scientific effectively reduce construction costs.

\section{The Method to Control the Cost of Construction Project}

Modern society increasingly demanding high quality architectural decoration, in order to meet the needs of market development, building decoration enterprises must strengthen the quality of staff training, provide the basis for reducing the cost of the project. Building renovation is a systematic project, the construction process is complicated, the construction surface is also very wide, but construction personnel with professional knowledge are extremely scarce. Therefore, construction and fitting unit must attach great importance to the quality of the training staff, only with a large number of construction personnel in order to enhance the overall strength of the construction and fitting unit fundamentally. For now the basic quality of construction and fitting's point of view, China's comprehensive literacy decorators are still many problems. To this end, China's higher vocational colleges should be created with the construction and fitting-related professional, targeted to cultivate specialized talents renovated; In addition, the building decoration enterprises should attach great importance to the role of training mechanisms, professional and technical personnel to carry out renovation workers one quality training to enhance the quality of decoration and construction workers on-site control of the importance of understanding the culture decoration talents with professional, cost of control of the business to provide security personnel.

Number of building renovation construction decoration materials used very much, according to the data show: the total cost of construction material construction cost $1 / 2$. Therefore, the unit must attach great importance to building renovation and refurbishing materials cost control, in order to significantly reduce the cost of the entire construction project to provide reliable protection. Building on the current status of the management units decoration materials point of view, there are still substandard decoration materials quality problems. Therefore, construction and fitting units should intensify efforts to control the quality of decoration materials. First, we should arrange for professionals engaged in decoration materials purchase, to reduce the quality, type and specification with substandard materials in use; in addition, material purchase officers in the purchase process should adhere to the principle of "cost control" and choose quality excellent inexpensive material; secondly, the material should also be combined with the optional staff development needs of modern society, to choose a non-polluting, low price and good quality material. Before signing the purchase contract, the factory should also check the material proof and quality assurance, reduce substandard quality of construction materials into the construction. Finally, the construction units should also attach great importance to the decoration decoration materials transport and stacking, arrange for professionals regularly check the quality of materials purchased. The decoration process there may be material to replace the problem needs to be replaced if a process material, the person concerned must be allowed to pass and signed to be replaced

Architectural decoration construction process is more complex, there are countless ties between the renovation process and the various other construction, any part of a problem, the overall quality of the building will have a greater impact. In order to reduce construction costs, guarantee the overall quality of engineering, construction and fitting units must strictly control the quality of the construction process. First, the organization should focus on the development of architectural decoration construction process, combined with the actual needs of the construction, the 
development of regulations and in accordance with the construction process should be followed, construction workers must strictly follow the implementation of the requirement decoration construction; Second, strengthen the quality inspection work. Decoration unit should be on the quality of the construction process to test various aspects of the construction process may occur in the analysis part of the problem, development of contingency plans, and strive for the first time to solve the decoration and construction quality problems; In addition, the quality control of the construction process to It targeted. Renovated units should arrange professional and technical personnel of various aspects of the construction site for comparison and analysis, identify the aspects to be controlled; renovated units also should have been identified control points for analysis, reducing quality problems caused by improper construction process produced for the cost control efforts to provide effective protection.

\section{Conclusion}

Building construction is a complex holistic work, especially after China's accession to WTO, the domestic construction units facing greater international competition, and only continue to improve project quality and ensure progress of the project and reduce construction costs and improve the economic efficiency of the construction unit, construction units to continuously improve international competitiveness, the construction unit should be in the actual project, and continue to explore coordination between security and the quality of construction between construction costs, making it an organic composition, trying to find methods to reduce construction costs and ways to further enhance the market competitiveness of the construction unit.

\section{Reference:}

[1] PM. A Guide to the Project. Management [M]. Body of Knowledge. 2000.

[2] Franeis M. Webster. Project Management Institute [M]. According to the Old Curmudgeon. 2000.

[3] Thomas C. Belangery. How to Plan Any Project [M]. Sterling Planning Group. 1995.

[4] Davidson Frame. New Project Management [M]. Jossey a BassIne, Publishers. 1994. 